\title{
Maternal phthalate exposure and asthma, rhinitis and eczema in 552 children aged 5 years; a prospective cohort study
}

Camilla Jøhnk', Arne Høst ${ }^{2}$, Steffen Husby², Greet Schoeters ${ }^{3,4}$, Clara Amalie Gade Timmermann ${ }^{1}$, Henriette Boye Kyhl ${ }^{2,5}$, Iben Have Beck', Anna-Maria Andersson ${ }^{6,7}$, Hanne Frederiksen ${ }^{6,7}$ and Tina Kold Jensen ${ }^{1,2,5^{*}}$

\begin{abstract}
Background: Prenatal phthalate exposure has been suggested to alter immune responses and increase the risk of asthma, eczema and rhinitis. However, few studies have examined the effects in prospective cohorts and only one examined rhinitis. We therefore studied associations between maternal urinary concentrations of phthalate metabolites and asthma, eczema and rhinitis in offspring aged 5 years.

Methods: From 552 pregnant women in the Odense Child Cohort, we quantified urinary concentrations of 12 phthalate metabolites in third trimester. We assessed asthma, rhinitis and eczema in their offspring at age 5 years with a questionnaire based on the International Study of Asthma and Allergies in Childhood (ISAAC), and conducted logistic regression adjusting for relevant confounders.

Results: $7.4 \%$ of the children had asthma, $11.7 \%$ eczema and 9.2\% rhinitis. Phthalate exposure was low compared to previous cohorts. No significant associations between prenatal phthalate exposure and asthma were found. Odds ratios (ORs) of child rhinitis with a doubling in $\Sigma D_{N} P_{m}$ and di-2-ethylhexyl phthalate metabolite $\left(\Sigma D E H P_{m}\right)$ concentrations were, respectively, 1.15 (95\% confidence interval (Cl) 0.97,1.36) and 1.21 (Cl 0.93,1.58). The OR of eczema when doubling $\Sigma D_{i N P}$ was 1.24 (Cl 1.00,1.55), whereas the OR of using medicine against eczema when doubling a di-ethyl phthalate (DEP) metabolite was 0.81 (Cl 0.68,0.96).

Conclusion: The lack of association between maternal phthalate exposure and asthma in the offspring may be due to low exposure and difficulties in determining asthma in 5-year-olds. The higher odds of rhinitis may raise public concern but further research in larger cohorts of older children is warranted.
\end{abstract}

Keywords: Phthalate exposure, Endocrine disrupting chemicals, Asthma, Allergic rhinitis, Eczema

\section{Background}

Asthma is the most common chronic condition among children with an estimated lifetime prevalence on $12 \%$ in Danish 5-year olds [1]. It is commonly seen in a triad with atopic dermatitis and allergic rhinitis. The lifetime

\footnotetext{
* Correspondence: tkjensen@health.sdu.dk

'Department of Environmental Medicine, Institute of Public Health, University of Southern Denmark, J.B. Winsløwsvej 17A, 5000 Odense, Denmark

${ }^{2}$ Hans Christian Andersen Children's Hospital, Odense University Hospital, Odense, Denmark

Full list of author information is available at the end of the article
}

prevalence [1] of atopic dermatitis at age 5 years in $\mathrm{Da}$ nish children is $13 \%$, and of rhinoconjunctivitis it is $7 \%$. Asthma is characterized by recurrent airway obstruction and bronchial hyper-responsiveness [2]. In many asthmatic children, wheezing and respiratory symptoms can be traced back to early childhood [3]. The diagnosis in young children is symptom based, as they cannot collaborate in spirometry [2]. However, asthma symptoms resemble symptoms of common infections like bronchitis.

(c) The Author(s). 2020 Open Access This article is licensed under a Creative Commons Attribution 4.0 International License, which permits use, sharing, adaptation, distribution and reproduction in any medium or format, as long as you give appropriate credit to the original author(s) and the source, provide a link to the Creative Commons licence, and indicate if changes were made. The images or other third party material in this article are included in the article's Creative Commons licence, unless indicated otherwise in a credit line to the material. If material is not included in the article's Creative Commons licence and your intended use is not permitted by statutory regulation or exceeds the permitted use, you will need to obtain permission directly from the copyright holder. To view a copy of this licence, visit http://creativecommons.org/licenses/by/4.0/ The Creative Commons Public Domain Dedication waiver (http://creativecommons.org/publicdomain/zero/1.0/) applies to the data made available in this article, unless otherwise stated in a credit line to the data. 
Phthalates are synthetic chemical compounds used as plasticizers in consumer products. They form weak chemical bonds and are easily leached into the surrounding environment, and they can cross the placenta and affect the fetus [4]. Phthalates have short biological half-lives from hours to a few days, but because exposure is ubiquitous, exposure levels may be relatively constant $[5,6]$. We identified 14 prospective cohort studies [5, 7-19] examining the association between prenatal phthalate exposure and asthma or allergy. Findings are inconsistent probably because different metabolites have been measured and the age of the children varied. Three studies $[9,11,16]$ measured metabolites of diisononyl phthalate (DiNP) and only one [13] studied rhinitis.

To our knowledge, no Scandinavian prospective cohort studies have examined the association between in utero phthalate exposure and development of asthma and allergy, and we therefore used data from a prospective Danish birth cohort to examine the association between maternal urinary phthalate metabolite concentrations in third trimester and development of asthma, eczema and rhinitis in 552 offspring aged 5 years.

\section{Materials and methods}

\section{Study settings and participants}

From 2010 to 2012 all newly pregnant women residing in Odense were invited to participate in the Odense Child Cohort (OCC) at Odense University Hospital between gestational age (GA) 10-16 weeks (earlier described in detail [20]). Information on maternal pre-pregnancy Body Mass Index (BMI), maternal educational level and maternal smoking during pregnancy was obtained through questionnaires during pregnancy. Data on birth characteristics, maternal age, parity at inclusion and GA was obtained from hospital records. Preterm was defined as born before GA 37 weeks. Information on breastfeeding, smoking, pets and family history of asthma and allergy was obtained from questionnaires during the first 5 life years.

\section{Phthalate metabolite measurements}

At approximately GA 28 weeks 870 pregnant women delivered a fasting spot urine sample for analysis of total content (free and conjugated) of 12 phthalate metabolites, of which some were summed (previously published [21]). The 4 di-2ethylhexyl phthalate (DEHP) metabolites mono-2-ethylhe xyl phthalate (MEHP), mono-2-ethyl-5-hydroxyhexyl phthal ate (MEHHP), mono-2-ethyl-5-oxohexyl phthalate (MEOH P), mono-2-ethyl-5-carboxypentyl phthalate (MECPP) where measured and summed as $\Sigma \mathrm{DEHP} \mathrm{m}_{\mathrm{m}}$ by addition of the molar sum of the four metabolites multiplied by the molecular weight of DEHP. Likewise, the 4 measured DiNP metabolites; mono-iso-nonyl phthalate (MiNP), monohydroxy-iso-nonyl phthalate (MHiNP), mono-oxo-iso-nonyl phthalate (MOiNP) and mono-carboxy-iso-octyl phthalate
(MCiOP) were measured and summed as $\Sigma \mathrm{DiNP}_{\mathrm{m}}$. We measured mono-iso-butyl phthalate (MiBP) and mono- $n$ butyl phthalate $(\mathrm{MnBP})$ and combined them as $\mathrm{MBP}_{\mathrm{i}+\mathrm{n}}$, since the two metabolites have been shown to be highly correlated in the urine of the women of Odense Child Cohort [22, 23]. Finally, we measured mono-benzyl phthalate $(\mathrm{MBzP})$ and monoethyl phthalate (MEP). Moderate to high correlation between all summed metabolites has been shown elsewhere [23]. Preparation and storage of standard solutions and samples, instrumental LC-MS/MS analysis and general method validation has previously been described [22].

To correct for urinary dilution, all samples with a phthalate metabolite concentration above the limit of detection (LOD) were osmolality adjusted. Osmolality was measured by the freezing point depression method [24]. All measured urinary concentrations were subsequently normalized to the group median osmolality $(0.63 \mathrm{x} \mathrm{osm} /$ $\mathrm{kg}$ ) using the following equation:

$$
\text { Osmolality adj.conc. }(\mathrm{ng} / \mathrm{mL})=\frac{\text { urinary conc. }(\mathrm{ng} / \mathrm{mL}) \times 0.63(\mathrm{osm} / \mathrm{kg})}{\text { sample osmolality }(\mathrm{osm} / \mathrm{kg})}
$$

This adjustment method was chosen because osmolality is less affected by other exogenous factors than other adjustment methods [25]. Concentrations below the LOD were substituted by the metabolite specific LOD divided by the square root of 2 .

\section{Measurement of asthma and allergy}

A Danish modified version of The International Study of Asthma and Allergies in Childhood (ISAAC) was administered at the 5 years' examination. Asthma outcomes were wheeze within the last 2 years, self-reported asthma, doctor diagnosed asthma and use of medicine to treat asthma/cold within the last 12 months. Self-reported asthma was defined as at least 3 episodes of wheeze (each lasting more than a day) within the last year. We used three different eczema outcomes; self-reported eczema, doctor-diagnosed eczema and use of prescribed medicine against atopic dermatitis or eczema of flexural folds. Selfreported eczema was defined as itchy symmetric eczema in the flexural folds behind the knees (which possibly came and disappeared again) within the last 6 months. Doctor diagnosed and use of prescribed medicine encountered all five life years, not just the last 6 months. Finally, we studied self-reported and doctor-diagnosed rhinitis defined as problems with recurrent sneezing and/or runny nose without having a cold or the flu and ever doctor diagnosed with hay fever. Due to a very low prevalence $(1.3 \%)$ of doctor-diagnosed rhinitis, we did not study this outcome. Doctor diagnosed outcomes were all parental report of doctor's diagnosis. 


\section{Data analysis}

The children included in this study were first compared to the rest of the OCC population with regard to child- and upbringing characteristics using t-tests and chi2-tests for continuous and categorical variables, respectively. We then compared characteristics among participating children with and without asthma, eczema or rhinitis using the same tests. Median and 25-75 percentiles of phthalate metabolite concentrations were compared according to the mother-child and upbringing characteristics and differences in the distribution assessed by Mann Whitney and Kruskal-Wallis test. Furthermore, Kruskal Wallis test was used to test for differences in maternal phthalate metabolite concentrations between children with two, one and no allergic outcomes.

The distribution of phthalate metabolite concentrations was right-skewed and transformed by the natural logarithm $(\mathrm{ln})$ to normalize distribution. The associations between $\ln$ transformed phthalate exposure and allergic outcomes were assessed using logistic regression. Phthalate metabolite concentrations were then back transformed to study the odds ratios (OR) for a doubling of phthalate exposure. We identified potential confounders using a directed acyclic graph based on existing literature (Fig. 1). Maternal age, educational level and parity were a priori expected to influence both exposure to phthalates and development of asthma, eczema and rhinitis and adjusted for in the final model to reduce model variance. Having a parent or sibling with allergy is a strong predictor for childhood allergy and was therefore included in the final model. In utero exposure to maternal smoking is a well-known risk factor for development of asthma, eczema and rhinitis, however, only $3 \%$ of mothers smoked during pregnancy, and this was therefore not included in the final model. To evaluate sex interactions, the interaction term of sex and phthalate metabolite were added in each model. However, the interaction was not significant, and was therefore removed from the final model.

Statistical analyses were conducted using STATA/IC 15.0 , and $p$-values $<0.05$ were considered significant.

\section{Results}

Totally, 846 women had phthalate metabolites measured in their urine and 1316 parents of singleton children answered the questions about asthma at age 5 years. Finally, 552 mother-child pairs with phthalate metabolite measurements and information about asthma, eczema and rhinitis were available for inclusion. The participants did not differ from the rest of OCC, however, a smaller proportion of the included mothers smoked during pregnancy (data not shown). The included mothers were on

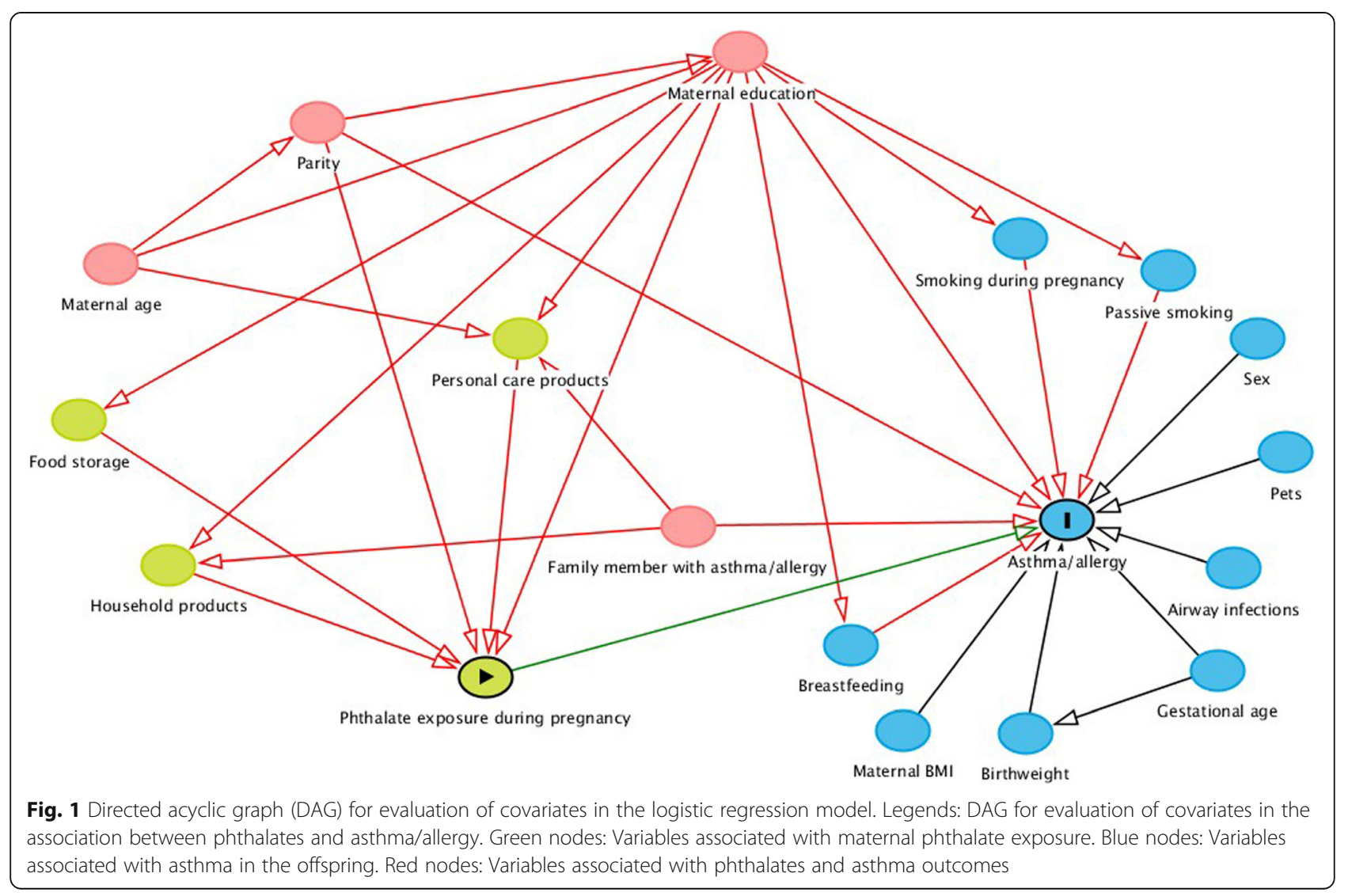


average 31 years old when giving birth and 58\% were nullipara (Table 2).

We found that $22.3 \%$ of the children had experienced wheeze. Combining self-reported and doctor-diagnosed asthma, the prevalence of asthma was $7.4 \%$. In total, $11.7 \%$ had self-reported eczema, whereas $9.2 \%$ reported rhinitis (Table 1). Furthermore, $3.3 \%$ of the children had both rhinitis and one of the eczema outcomes and 1.7\% had rhinitis and one asthma outcome. Only 4 children $(0.8 \%)$ had an asthma outcome and an eczema outcome.

Mothers of children with doctor diagnosed asthma had higher BMI and more often had pets. Preterm children wheezed more than children born at term, and children with a birth weight less than $2500 \mathrm{~g}$ more often had selfreported asthma compared to children with higher birth weight. Significantly more boys were doctor-diagnosed with asthma and had self-reported rhinitis. The prevalence of wheeze, self-reported asthma, doctor diagnosed asthma and self-reported rhinitis were higher between children with a family history of asthma compared to children without a family history of asthma. Maternal age and parity showed no significant association with asthma, rhinitis or eczema in our study (Table 2).

To examine the levels of phthalate exposure, we measured the urinary phthalate concentrations and calculated the percentage of pregnant women who excreted levels above LOD. Phthalate metabolites were detectable in more than $90 \%$ of urine samples, except MBzP, which was detected in $68 \%$ of the samples (Table 3). Mothers with high or low BMI excreted significantly higher concentrations of phthalate metabolites than normal weight women (Table 4), otherwise no differences in maternal and child characteristics according to phthalate exposure were found.

We then compared urinary phthalate concentrations in mothers of children with an allergic outcome to urinary concentrations in mothers of children without the outcome to detect differences. No significant differences in phthalate concentrations were found between children with and

Table 1 Prevalence of allergic outcomes

\begin{tabular}{ll}
\hline Outcome & Prevalence \\
\hline Wheeze within the last 2 years & $22.3 \%$ \\
Self-reported asthma & $4.7 \%$ \\
Doctor-diagnosed asthma & $5.1 \%$ \\
Use of medicine against asthma/cold & $13.8 \%$ \\
Self-reported eczema & $11.7 \%$ \\
Doctor-diagnosed eczema & $6.6 \%$ \\
Medicine against eczema & $6.2 \%$ \\
Self-reported rhinitis & $9.2 \%$ \\
Rhinitis and eczema & $3.3 \%$ \\
Rhinitis and asthma & $1.7 \%$ \\
Asthma and eczema & $0.8 \%$ \\
\hline
\end{tabular}

without asthma or eczema. Compared to children without rhinitis, children with self-reported rhinitis had been exposed to higher levels of DiNP, DEHP and DBP prenatally (only significant for DiNP). In contrast, mothers of children with asthma, rhinitis or eczema tended to have lower concentrations of MEP compared to mothers of non-allergic children (Table 5). No differences in urinary phthalate concentrations between children with two allergic outcomes compared to children with one or no allergic outcomes were found (data not shown).

Finally, we examined the association between urinary phthalate concentrations and ORs of allergic outcomes to study patterns or possibly significant associations in the study population. In adjusted logistic regression no clear associations were found, however, most ORs for asthma outcomes were below one. Maternal MEP concentration was associated with reduced odds of self-reported ( $\mathrm{OR}=$ $0.81,95 \%$ CI: $0.68,0.96)$ and doctor diagnosed eczema $(\mathrm{OR}=0.82,95 \% \mathrm{CI}: 0.66,1.01)$ in the offspring. A doubling in $\Sigma \mathrm{DiNP}_{\mathrm{m}}$ tended to increase the odds of using medication to treat eczema $(\mathrm{OR}=1.24,1.00,1.55)$. A doubling in $\Sigma \mathrm{DiNP}_{\mathrm{m}}$ and $\Sigma \mathrm{DEHP} \mathrm{P}_{\mathrm{m}}$ concentration increased the odds of having self-reported rhinitis, although not statistically significant $(\mathrm{OR}=1.15,95 \% \mathrm{CI}: 0.97,1.36$ and $\mathrm{OR}=1.21$, 95\% CI: 0.93,1.58, respectively) (Table 6).

\section{Discussion}

In this prospective cohort with lower phthalate exposure than similar previously reported cohorts $[7,8,12,18,19]$ we found no consistent associations between prenatal phthalate exposure and allergic outcomes in the offspring aged 5 years. Interestingly, prenatal DiNP and DEHP exposure tended to increase the risk of rhinitis, although not statistically significant. DEP exposure, measured as urinary MEP concentration, decreased the odds of eczema, while DiNP exposure tended to increase it. The reduction in eczema among DEP exposed may be explained by avoidance behavior, as mothers in families with a history of asthma/allergy had lower MEP-concentrations than mothers in families without asthma/allergy, indicating that they may use less creams and cosmetics containing DEP [26]. In contrast, DiNP is difficult to avoid, as it is found in flooring, building material etc. [4], and we found no differences in DiNP metabolite concentrations between mothers in predisposed and non-disposed families. However, mothers from families with a history of asthma/allergy did not have significantly lower MEP-concentrations compared to mothers from families without, so other parameters may play a role in the association.

Nine cohort studies [7, 8, 10, 14-19] examined the association between prenatal phthalate exposure and wheeze and asthma. Some $[8,10,14,16,17,19]$ found association between maternal MnBP and DEHP metabolites and increased risk of wheeze or asthma in children 
Table 2 Characteristics (percent distribution) of the mother-child pairs according to allergic outcomes

\begin{tabular}{|c|c|c|c|c|c|c|c|c|c|c|c|}
\hline \multirow[t]{2}{*}{ Characteristics } & \multirow[t]{2}{*}{$\begin{array}{l}\text { n (\%) } \\
552(100)\end{array}$} & \multicolumn{2}{|c|}{$\begin{array}{l}\text { Wheeze within the } \\
\text { last } 2 \text { years }(n=552)\end{array}$} & \multicolumn{2}{|c|}{$\begin{array}{l}\text { Self-reported } \\
\text { asthma( }(n=535)\end{array}$} & \multicolumn{2}{|c|}{$\begin{array}{l}\text { Doctor-diagnosed } \\
\text { asthma }(n=530)\end{array}$} & \multicolumn{2}{|c|}{$\begin{array}{l}\text { Self-reported } \\
\text { rhinitis }(n=532)\end{array}$} & \multicolumn{2}{|c|}{$\begin{array}{l}\text { Self-reported } \\
\text { eczema }(n=487)\end{array}$} \\
\hline & & $\begin{array}{c}\text { Yes } \\
n=123\end{array}$ & $\begin{array}{c}\text { No } \\
n=429\end{array}$ & $\begin{array}{c}\text { Yes } \\
n=25\end{array}$ & $\begin{array}{c}\text { No } \\
n=510\end{array}$ & $\begin{array}{l}\text { Yes } \\
n=27\end{array}$ & $\begin{array}{c}\text { No } \\
n=503\end{array}$ & $\begin{array}{c}\text { Yes } \\
n=49\end{array}$ & $\begin{array}{c}\text { No } \\
n=483\end{array}$ & $\begin{array}{l}\text { Yes } \\
(57)\end{array}$ & $\begin{array}{r}\text { No } \\
(430)\end{array}$ \\
\hline \multicolumn{12}{|l|}{ Sex } \\
\hline Boy & $278(50.4)$ & 54.5 & 49.2 & 48.0 & 51.2 & 70.4 & 49.5 & 67.3 & 48.2 & 43.9 & 52.3 \\
\hline Girl & $274(49.6)$ & 45.5 & 50.8 & 52.0 & 48.8 & $29.6^{*}$ & $50.5^{*}$ & $32.7^{*}$ & $51.8^{*}$ & 56.1 & 47.7 \\
\hline \multicolumn{12}{|l|}{ Birth weight (grams) } \\
\hline$<2500$ & $13(2.4)$ & 4.1 & 1.9 & $8.0^{*}$ & $2.2^{*}$ & 7.4 & 2.2 & 4.1 & 2.3 & 0.0 & 2.6 \\
\hline $2500-4000$ & $435(78.8)$ & 74.8 & 80.0 & 56.0 & 80.0 & 66.7 & 79.1 & 71.4 & 79.9 & 73.7 & 80.2 \\
\hline$>4000$ & $104(18.8)$ & 21.1 & 18.2 & $36.0^{*}$ & $17.8^{*}$ & 25.9 & 18.7 & 24.5 & 17.8 & 26.3 & 17.2 \\
\hline \multicolumn{12}{|l|}{ Preterm birth (<week 37) } \\
\hline Yes & $24(4.3)$ & $8.9^{*}$ & $3.0^{*}$ & 8.0 & 4.1 & 7.4 & 4.2 & 6.1 & 4.1 & 1.8 & 4.7 \\
\hline No & $528(95.7)$ & 91.1 & 97.0 & 92.0 & 95.9 & 92.6 & 95.8 & 93.9 & 95.9 & 98.2 & 95.3 \\
\hline \multicolumn{12}{|c|}{ Maternal age at delivery (years) } \\
\hline$<25$ & $50(9.1)$ & 13.0 & 7.9 & 8.0 & 9.2 & 11.1 & 8.9 & 6.1 & 9.5 & 15.8 & 9.3 \\
\hline $25-29$ & $193(35.0)$ & 35.8 & 34.7 & 40.0 & 34.7 & 29.6 & 35.2 & 36.7 & 34.6 & 26.3 & 36.3 \\
\hline $30-34$ & $210(38.0)$ & 33.3 & 39.4 & 32.0 & 38.4 & 37.0 & 38.4 & 36.7 & 37.9 & 36.8 & 37.4 \\
\hline$\geq 35$ & $99(17.9)$ & 17.9 & 17.9 & 20.0 & 17.6 & 22.2 & 17.5 & 20.4 & 18.0 & 21.1 & 17.0 \\
\hline \multicolumn{12}{|l|}{ BMI $\left(\mathrm{kg} / \mathrm{m}^{2}\right)$} \\
\hline$<20$ & $59(10.7)$ & $10.6^{*}$ & $10.7^{*}$ & 0.0 & 11.2 & $11.1^{*}$ & $10.7^{*}$ & 12.2 & 10.1 & 14.0 & 10.9 \\
\hline $20-25$ & $286(51.8)$ & 42.3 & 54.5 & 48.0 & 52.4 & 22.2 & 53.7 & 38.8 & 52.6 & 38.6 & 53.7 \\
\hline$\geq 25$ & $207(37.5)$ & $47.2^{*}$ & $34.7^{*}$ & 52.0 & 36.5 & $66.7^{*}$ & $35.6^{*}$ & 49.0 & 37.3 & 47.4 & 35.3 \\
\hline \multicolumn{12}{|l|}{ Parity } \\
\hline Nulliparous & $321(58.2)$ & 65.0 & 56.2 & 64.0 & 57.5 & 51.9 & 57.7 & 61.2 & 57.8 & 63.2 & 58.4 \\
\hline Multiparous & $231(41.8)$ & 35.0 & 43.8 & 36.0 & 42.5 & 48.1 & 42.3 & 38.8 & 42.2 & 36.8 & 41.6 \\
\hline \multicolumn{12}{|l|}{ Smoking during pregnancy } \\
\hline Yes & $16(2.9)$ & 3.3 & 2.8 & 4.0 & 2.9 & 3.7 & 3.0 & 6.1 & 2.7 & 1.8 & 2.8 \\
\hline No & $536(97.1)$ & 97.7 & 97.2 & 96.0 & 97.0 & 96.3 & 97.0 & 93.9 & 97.3 & 98.2 & 97.2 \\
\hline \multicolumn{12}{|l|}{ Education level at pregnancy } \\
\hline High school or less & $144(26.3)$ & $38.3^{*}$ & $23.0^{*}$ & $20.0^{*}$ & $26.5^{*}$ & 33.3 & 25.7 & 34.7 & 25.7 & 33.3 & 26.8 \\
\hline High school $+1-4$ years & $279(51.0)$ & 41.7 & 53.6 & 36.0 & 51.5 & 48.1 & 51.0 & 51.0 & 50.0 & 50.9 & 51.4 \\
\hline High school $+>4$ years & $124(22.7)$ & $20.0^{*}$ & $23.4^{*}$ & $44.0^{*}$ & $22.0^{*}$ & 18.5 & 23.3 & 14.3 & 24.3 & 15.8 & 21.8 \\
\hline \multicolumn{12}{|l|}{ Breastfeeding (weeks) } \\
\hline$<4$ & $45(9.4)$ & 9.1 & 9.2 & $13.6^{*}$ & $9.3^{*}$ & 9.1 & 9.2 & $13.3^{*}$ & $9.4^{*}$ & 9.8 & 10.2 \\
\hline $4-19$ & $88(18.4)$ & 27.3 & 17.7 & 36.4 & 16.8 & 27.3 & 17.7 & 33.3 & 16.8 & 17.6 & 18.7 \\
\hline$>19$ & $345(72.2)$ & 63.6 & 73.1 & $50.0^{*}$ & $73.9^{*}$ & 63.6 & 73.1 & $53.3^{*}$ & $73.8^{*}$ & 72.5 & 71.1 \\
\hline \multicolumn{12}{|c|}{ Family history of asthma/allergy } \\
\hline Yes & $309(56.0)$ & 61.8 & 54.3 & 68.0 & 55.4 & 63.0 & 55.6 & $72.9^{*}$ & $54.9^{*}$ & 69.6 & 56.5 \\
\hline No & $243(44.0)$ & 38.2 & 45.7 & 32.0 & 44.6 & 37.0 & 44.4 & 27.1 & 45.1 & 30.4 & 43.5 \\
\hline \multicolumn{12}{|l|}{ Family history of asthma } \\
\hline Yes & $115(20.8)$ & $30.1^{*}$ & $18.2^{*}$ & $48.0^{*}$ & $18.6^{*}$ & $44.4^{*}$ & $18.9^{*}$ & $30.6^{*}$ & $18.8^{*}$ & 26.3 & 19.5 \\
\hline No & $437(79.2)$ & 69.9 & 81.8 & 52.0 & 81.4 & 55.6 & 81.1 & 69.4 & 81.2 & 73.7 & 80.5 \\
\hline \multicolumn{12}{|l|}{ Pets (inside and outside) } \\
\hline Yes & $231(42.4)$ & 50.0 & 40.2 & $52.0^{*}$ & $42.3^{*}$ & $59.3^{*}$ & $41.7^{*}$ & 63.8 & 43.4 & 37.0 & 42.6 \\
\hline No & $314(57.6)$ & 50.0 & 59.8 & 48.0 & 57.7 & 40.7 & 58.3 & 36.2 & 56.6 & 63.0 & 57.4 \\
\hline
\end{tabular}

${ }^{*} p$-value $<0.05$ when testing for significant differences in distribution between the group with an allergic outcome and the group without (using t-test for continuous and chi2-test for categorical variables) 
Table 3 Urinary phthalate metabolite levels $[\mathrm{ng} / \mathrm{mL}]$ measured in gestational week 28

\begin{tabular}{|c|c|c|c|c|c|c|c|c|c|c|c|}
\hline \multirow{2}{*}{$\begin{array}{l}\text { Diether } \\
\text { phthalate }\end{array}$} & \multirow[t]{2}{*}{ Phthalate metabolite } & \multirow[t]{2}{*}{ LOD } & \multirow[t]{2}{*}{$\%>$ LOD } & \multirow[t]{2}{*}{ Mean } & \multirow[t]{2}{*}{ Minimum } & \multicolumn{5}{|c|}{ Percentile } & \multirow[t]{2}{*}{ Maximum } \\
\hline & & & & & & 5 th & 25th & 50th & 75th & 95 th & \\
\hline DEP & MEP & 0.53 & 99.8 & 103.8 & 0.37 & 2.6 & 7.3 & 17.9 & 55.8 & 351.5 & 5380.9 \\
\hline DiBP & MiBP & 1.10 & 99.6 & 37.1 & 0.78 & 3.4 & 12.3 & 27.1 & 47.2 & 104.1 & 455.2 \\
\hline \multirow[t]{2}{*}{ DnBP } & $\mathrm{MnBP}$ & 1.43 & 95.3 & 18.2 & $<\mathrm{LOD}$ & 1.5 & 6.0 & 13.5 & 24.9 & 51.7 & 184.3 \\
\hline & $\Sigma \mathrm{MBP}_{(\mathrm{i}+\mathrm{n})}$ & & & 55.3 & $<\mathrm{LOD}$ & 4.9 & 19.1 & 41.5 & 74.7 & 150.3 & 516.1 \\
\hline $\mathrm{BBz} \mathrm{P}$ & $\mathrm{MBzP}$ & 1.14 & 67.9 & 4.63 & & & $<\mathrm{LOD}$ & 2.5 & 5.8 & 15.7 & 71.2 \\
\hline \multirow[t]{5}{*}{ DEHP } & MEHP & 0.14 & 90.2 & 1.7 & & $<L O D$ & 0.46 & 1.1 & 2.2 & 5.5 & 36.8 \\
\hline & MEHHP & 0.91 & 89.3 & 6.6 & & $<\mathrm{LOD}$ & 2.2 & 51.0 & 8.6 & 18.5 & 92.7 \\
\hline & MEOHP & 0.67 & 91.5 & 5.4 & $<\mathrm{LOD}$ & $<\mathrm{LOD}$ & 1.8 & 4.3 & 7.0 & 14.6 & 56.6 \\
\hline & MECPP & 0.55 & 96.9 & 6.4 & $<\mathrm{LOD}$ & 0.73 & 2.4 & 5.2 & 8.5 & 15.6 & 95.7 \\
\hline & $\Sigma \mathrm{DEHP} \mathrm{m}_{\mathrm{m}}$ & & & 26.5 & $<\mathrm{LOD}$ & 1.5 & 9.4 & 21.4 & 34.6 & 69.0 & 305.0 \\
\hline \multirow[t]{5}{*}{ DiNP } & MiNP & 0.61 & 11.6 & 1.2 & & & & & $<L O D$ & 0.98 & 135.5 \\
\hline & MHiNP & 0.26 & 91.1 & 9.4 & & $<\mathrm{LOD}$ & 0.78 & 1.6 & 3.8 & 12.6 & 1433.4 \\
\hline & MOiNP & 0.25 & 83.3 & 5.0 & & $<L O D$ & 0.45 & 1.1 & 2.5 & 8.9 & 690.4 \\
\hline & MCiOP & 0.11 & 100.0 & 13.3 & 0.15 & 0.52 & 1.8 & 3.7 & 7.5 & 23.6 & 1438.4 \\
\hline & $\Sigma \mathrm{DiNP}_{\mathrm{m}}$ & & & 38.1 & 0.22 & 0.77 & 4.3 & 8.5 & 18.3 & 58.0 & 4956.8 \\
\hline
\end{tabular}

Abbreviations: $L O D$ Limit of detection; DEP Diethyl phthalate; DiBP Diisobutyl phthalate; DnBP Di-n-butyl phthalate; $B B z P$ Benzyl-butyl phthalate; $D E H P$ Di-2ethylhexyl phthalate; DiNP Diisononyl phthalate; MEP monoethyl phthalate; MiBP mono-isobutyl phthalate; MnBP mono-n-butyl phthalate; MBzP monobenzyl phthalate; MEHP mono-2-ethylhexyl phthalate; MEHHP mono-2-ethyl-5-hydroxyhexyl phthalate; MEOHP mono-2-ethyl-5-oxohexyl phthalate; MECPP mono-2-ethyl5-carboxypentyl phthalate; MiNP mono-iso-nonyl phthalate; MHiNP mono-hydroxy-iso-nonyl phthalate; MHiNP mono-hydroxy-iso-nonyl phthalate; MCiOP mono-carboxy-iso-octyl phthalate

aged 5-11 years. However, in one study [7] a higher DEP exposure decreased the risk of wheeze in girls aged 6-7 years. One study [15] found no associations between MEP, MnBP or MiBP and asthma. We did not find associations between phthalate exposure and asthma, probably because our mothers were less exposed and the diagnosis of asthma is difficult to verify before the children can collaborate [2].

Ten cohort studies $[5,7,9,11-16,19]$ examined the association between prenatal phthalate exposure and eczema. Two studies $[14,16]$ measured exposure in serum and detected an association between high concentration of MEHP and DiNP metabolites and decreased risk of eczema. Three studies [11-13] found that higher urinary concentrations of MBzP, MEP, MiBP and $\mathrm{DDEHP}_{\mathrm{m}}$ was associated with increased odds of eczema in 2-5 years old children. One study [5] suggested that higher urinary MBzP concentration increased the risk of eczema in 2-year old but not 5year old children. Among Polish 2-year-olds, neither MEP, $\mathrm{MBP}, \Sigma \mathrm{DiNP}_{\mathrm{m}}$ nor $\Sigma \mathrm{DEHP} \mathrm{m}_{\mathrm{m}}$ were associated with eczema [9]. In our cohort DiNP exposure tended to increase the risk of using medicine against eczema, despite low exposure. Three studies [7, 15, 19] examined MEP and MBP and eczema in 7-year-olds, and found no associations possibly because eczema often resolves at child age 6-7 years [27].

One study [15] found no association between maternal urinary concentrations of $\mathrm{MEP}, \mathrm{MnBP}$ and $\mathrm{MiBP}$ and rhinitis in the offspring aged 3 years. To our knowledge, we are the first to report association between prenatal DiNP and DEHP exposure and rhinitis in 5-year-old children, but our findings need confirmation in larger cohorts of older children.

Phthalates are hypothesized to interfere with the immune and respiratory systems and promote the hyperresponsiveness seen in atopic diseases [28]. In vitro, DEHP promotes Th2 polarization and enhances interleukin [28, 29], which causes IgE-production, smooth muscle contractility and mucus production [30]. Furthermore, DEHP interacts with the nuclear hormone receptor family peroxisome proliferator-activated receptors, affecting alveolar maturation and reducing surfactant production, altering lung mechanics [31]. Animal studies indicate that early life exposure to DEHP results in proinflammatory immune responses [32].

Our study was large, population-based and prospective establishing temporal relationship between phthalate exposure and allergic disease. However, our children are most likely healthier than the general population as the prevalence of asthma was $7.4 \%$, whereas it is $12 \%$ based on hospital contacts and disease-specific prescribed medications in a large study of Danish 5-year-old children [1]. The participation rate in OCC was $43 \%$, and participating mothers were older and more often nonsmokers compared to not participating mothers [20]. As young maternal age and smoking are well known risk factors for asthma this may explain the lower prevalence of asthma in our study [33]. 
Table 4 Maternal median (25-75 percentile) osmolality adjusted urinary phthalate metabolite concentrations according to mother/ child characteristics

\begin{tabular}{|c|c|c|c|c|c|}
\hline Characteristics & $\mathrm{n}$ & $\begin{array}{l}\text { MEP Median and } \\
\text { 25-75th percentile } \\
(\mathrm{ng} / \mathrm{ml})\end{array}$ & $\begin{array}{l}\sum \mathrm{MBP}_{\mathrm{i}+\mathrm{n}} \text { Median and } \\
25-75 \text { th percentile } \\
(\mathrm{ng} / \mathrm{ml})\end{array}$ & $\begin{array}{l}\text { ¿DEHP } m \text { Median and } \\
\text { 25-75th percentile } \\
(\mathrm{ng} / \mathrm{ml})\end{array}$ & $\begin{array}{l}\sum_{\text {DiNP }} \text { Median and } \\
\text { 25-75th percentile } \\
(\mathrm{ng} / \mathrm{ml})\end{array}$ \\
\hline \multicolumn{6}{|l|}{ Sex } \\
\hline Boy & 278 & $22.2(9.6-55.0)$ & $44.7(27.1-71.4)$ & $22.0(13.9-33.2)$ & $9.9(5.8-19.7)$ \\
\hline Girl & 274 & $19.6(8.8-51.9)$ & $43.7(26.3-69.2)$ & $21.8(12.5-31.9)$ & $8.6(5.1-15.8)$ \\
\hline \multicolumn{6}{|c|}{ Birth weight (grams) } \\
\hline$<2500$ & 13 & $13.4(6.8-20.9)$ & $37.7(30.2-44.1)$ & $20.2(15.8-22.3)$ & $7.2(6.3-19.2)$ \\
\hline $2500-4000$ & 435 & $22.6(9.8-51.9)$ & $45.2(27.2-68.5)$ & $22.3(13.5-33.0)$ & $9.0(5.4-17.6)$ \\
\hline$\geq 4000$ & 104 & $16.6(8.0-65.6)$ & $42.5(25.7-73.5)$ & $20.8(12.3-30.1)$ & $10.8(5.1-20.4)$ \\
\hline \multicolumn{6}{|c|}{ Preterm (<week 37) } \\
\hline Yes & 24 & $17.8(9.9-72.5)$ & $40.9(28.8-70.1)$ & $20.8(12.0-27.2)$ & $9.5(5.7-20.7)$ \\
\hline No & 528 & $21.4(9.1-52.4)$ & $44.5(26.6-70.0)$ & $22.0(13.5-32.9)$ & $9.2(5.4-18.3)$ \\
\hline \multicolumn{6}{|c|}{ Age at birth (year) } \\
\hline$<25$ & 50 & $20.6(8.9-37.7)$ & $44.3(24.3-70.0)$ & $20.4(14.7-33.0)$ & $9.3(4.5-14.3)$ \\
\hline $25-29$ & 193 & $19.8(9.8-47.7)$ & $40.5(26.1-66.2)$ & $21.2(11.2-31.3)$ & $9.1(5.1-19.3)$ \\
\hline $30-34$ & 210 & $20.5(8.9-55.0)$ & $45.0(26.6-70.4)$ & $21.7(14.2-32.5)$ & $9.3(5.7-15.5)$ \\
\hline$\geq 35$ & 99 & $25.2(8.8-94.8)$ & $52.1(35.7-75.1)$ & $24.0(13.8-34.7)$ & $9.2(6.4-19.7)$ \\
\hline \multicolumn{6}{|l|}{$\mathrm{BMI}\left(\mathrm{kg} / \mathrm{m}^{2}\right)$} \\
\hline$<20$ & 59 & $26.1(10.6-55.0)$ & $49.1(30.2-72.5)^{*}$ & $22.0(15.0-29.3)^{*}$ & $7.4(5.0-19.3)^{*}$ \\
\hline $20-25$ & 286 & $19.5(8.7-46.9)$ & $40.4(22.4-63.0)$ & $20.4(11.6-31.0)$ & $8.4(5.0-14.8)$ \\
\hline$\geq 25$ & 207 & $25.4(9.3-65.4)$ & $49.9(30.5-75.4)^{*}$ & $24.0(15.8-39.8)^{*}$ & $11.5(6.6-20.5)^{*}$ \\
\hline \multicolumn{6}{|l|}{ Parity } \\
\hline Nulliparous & 321 & $20.9(10.4-50.0)$ & $44.9(27.0-69.4)$ & $21.8(13.4-33.0)$ & $9.5(5.4-19.2)$ \\
\hline Multiparous & 231 & $21.4(8.6-61.5)$ & $43.9(26.5-70.1)$ & $22.0(13.5-32.1)$ & $9.1(5.2-15.8)$ \\
\hline \multicolumn{6}{|l|}{ Smoking } \\
\hline Yes & 16 & $26.2(7.9-69.2)$ & $48.2(25.8-76.4)$ & $24.1(15.7-35.8)$ & $11.4(4.7-20.4)$ \\
\hline No & 536 & $21.0(9.3-52.5)$ & $44.4(26.7-69.7)$ & $21.9(13.5-32.4)$ & $9.2(5.4-18.3)$ \\
\hline \multicolumn{6}{|c|}{ Education level years } \\
\hline Low & 144 & $25.4(10.6-65.6)$ & $48.5(29.7-75.6)$ & $24.0(13.5-39.0)$ & $10.2(6.0-20.7)$ \\
\hline Intermediate & 279 & $19.8(8.8-55.8)$ & $43.0(25.3-66.9)$ & $21.4(13.5-31.0)$ & $9.0(5.5-16.8)$ \\
\hline High & 124 & $19.8(9.1-39.6)$ & $45.8(29.4-73.2)$ & $21.7(12.9-31.6)$ & $8.5(4.9-19.1)$ \\
\hline \multicolumn{6}{|l|}{ Breastfeeding } \\
\hline$<4$ weeks & 45 & $17.0(9.0-53.2)$ & $48.1(36.1-75.2)$ & $24.8(13.7-33.4)$ & $10.3(7.0-21.2)$ \\
\hline 4-19 weeks & 88 & $30.3(14.2-91.4)$ & $49.9(31.5-67.5)$ & $20.7(15.2-32.8)$ & $12.8(7.0-19.9)$ \\
\hline$>19$ weeks & 419 & $20.4(9.3-49.2)$ & $43.3(25.7-70.1)$ & $21.8(13.1-32.1)$ & $8.6(5.1-17.2)$ \\
\hline \multicolumn{6}{|c|}{ Family history of asthma/allergy } \\
\hline Yes & 309 & $19.5(8.4-49.9)$ & $44.4(27.2-68.5)$ & $21.6(13.0-32.4)$ & $9.7(5.3-20.3)$ \\
\hline No & 239 & $23.2(10.9-56.9)$ & $44.2(26.0-71.1)$ & $22.3(13.6-32.8)$ & $8.4(5.4-14.8)$ \\
\hline \multicolumn{6}{|c|}{ Family history of asthma } \\
\hline Yes & 115 & $22.2(8.1-54.1)$ & $41.2(26.7-68.5)$ & $21.2(13.0-32.4)$ & $9.0(5.1-20.0)$ \\
\hline No & 437 & $20.9(10.2-52.5)$ & $45.2(26.6-70.0)$ & $22.1(13.5-32.5)$ & $9.2(5.6-18.0)$ \\
\hline
\end{tabular}

Abbreviations: $M E P$ monoethyl phthalate; $\Sigma M B P_{i+n}$ Monobutyl phthalate $(\mathrm{i}+\mathrm{n}) ; \Sigma D i N P_{m}$ sum of Di-isonyl phthalate metabolites; $\Sigma D E H P_{m}$ sum of Di-2-ethylhexyl phthalate metabolites

${ }^{*} p<0.05$ using Mann-Whitney test for difference between characteristics with 2 parameters, Kruskal-Wallis test for characteristics with more than 2 parameters 
Table 5 Maternal median (25-75 percentile) urinary phthalate metabolite concentrations among offspring with or without allergic outcomes

\begin{tabular}{|c|c|c|c|c|c|}
\hline Outcome & $\mathrm{n}$ & $\begin{array}{l}\text { MEP Median and } \\
25-75(\mathrm{ng} / \mathrm{mL})\end{array}$ & $\begin{array}{l}\sum \mathrm{MBP}_{\mathrm{i}+\mathrm{n}} \text { Median and } \\
25-75(\mathrm{ng} / \mathrm{mL})\end{array}$ & $\begin{array}{l}\sum_{\text {DEHP }} \text { Median and } \\
25-75(\mathrm{ng} / \mathrm{mL})\end{array}$ & $\begin{array}{l}\sum \text { DiNP }_{m} \text { Median and } \\
25-75(\mathrm{ng} / \mathrm{mL})\end{array}$ \\
\hline \multicolumn{6}{|c|}{ Wheeze within the last 2 years } \\
\hline Yes & 123 & $21.9(9.6-56.9)$ & $39.7(25.4-71.5)$ & $22.3(12.2-33.8)$ & $9.4(5.4-15.2)$ \\
\hline No & 429 & $20.3(9.0-51.9)$ & $45.2(27.0-70.0)$ & $21.8(13.7-32.3)$ & $9.2(5.4-19.1)$ \\
\hline \multicolumn{6}{|c|}{ Self-reported asthma } \\
\hline Yes & 25 & $19.3(12.7-67.2)$ & $41.9(30.2-71.5)$ & $22.3(13.9-33.8)$ & $10.7(5.1-22.3)$ \\
\hline No & 510 & $21.4(9.1-52.5)$ & $44.5(26.6-68.5)$ & $21.8(13.5-32.4)$ & $9.2(5.4-18.3)$ \\
\hline \multicolumn{6}{|c|}{ Doctor-diagnosed asthma } \\
\hline Yes & 27 & $16.4(6.8-55.5)$ & $36.9(18.3-74.2)$ & $23.1(9.3-31.9)$ & $10.3(4.0-22.3)$ \\
\hline No & 503 & $21.8(9.3-52.5)$ & $44.8(27.1-68.5)$ & $21.9(13.5-32.8)$ & $9.3(5.4-18.4)$ \\
\hline \multicolumn{6}{|c|}{ Use of medicine for asthma/cold } \\
\hline Yes & 76 & $21.8(10.3-66.3)$ & $38.7(30.0-64.2)$ & $20.6(9.6-32.6)$ & $8.6(5.0-14.1)$ \\
\hline No & 476 & $20.7(9.1-52.0)$ & $45.2(26.3-71.3)$ & $22.0(13.5-32.4)$ & $9.4(5.5-19.2)$ \\
\hline \multicolumn{6}{|c|}{ Self-reported eczema } \\
\hline Yes & 57 & $16.0(8.9-35.4)$ & $43.5(24.8-63.3)$ & $9.6(5.1-20.7)$ & $21.5(13.4-31.3)$ \\
\hline No & 430 & $22.2(10.2-55.5)$ & $44.5(27.2-68.5)$ & $9.4(5.5-19.0)$ & $22.2(13.7-33.4)$ \\
\hline \multicolumn{6}{|c|}{ Doctor-diagnosed eczema } \\
\hline Yes & 32 & $14.4(8.6-35.2)$ & $43.1(19.9-60.4)$ & $9.6(4.7-22.7)$ & $20.3(12.1-31.8)$ \\
\hline No & 455 & $22.2(9.7-55.0)$ & $44.6(27.2-69.2)$ & $9.4(5.5-18.8)$ & $22.3(13.8-33.2)$ \\
\hline \multicolumn{6}{|c|}{ Use of medicine against eczema } \\
\hline Yes & 24 & $18.2(8.57-38.8)$ & $40.0(23.6-62.5)$ & $11.0(4.7-36.1)$ & $21.4(13.4-32.7)$ \\
\hline No & 366 & $23.7(10.6-55.6)$ & $44.3(27.9-68.5)$ & $9.7(5.7-18.0)$ & $22.1(14.0-33.4)$ \\
\hline \multicolumn{6}{|c|}{ Self-reported rhinitis } \\
\hline Yes & 49 & $17.8(9.1-43.1)$ & $49.9(32.0-81.9)$ & $25.2(16.7-32.1)$ & $11.2^{\mathrm{a}}(7.1-21.5)$ \\
\hline No & 483 & $21.2(8.9-55.0)$ & $44.1(26.6-68.5)$ & $21.8(13.5-33.0)$ & $9.0(5.2-18.0)$ \\
\hline
\end{tabular}

Abbreviations: MEP monoethyl phthalate; $\Sigma M B P_{i+n}$ Monobutyl phthalate $(\mathrm{i}+\mathrm{n}) ; \Sigma D i N P_{m}$ sum of Di-isonyl phthalate metabolites; $\Sigma D E H P_{m}$ sum of Di-2-ethylhexyl phthalate metabolites

a Significant difference in urinary phthalate concentrations between the group that answered "yes" and the group that answered "no" (using Mann-Whitney test)

Table 6 Adjusted odds ratios and 95\% confidence interval for allergic outcomes

\begin{tabular}{lllll}
\hline Outcome & MEP OR and & $\begin{array}{c}\sum M B P \\
\text { OR and } 95 \% \mathrm{Cl}\end{array}$ & $\begin{array}{c}\sum \mathrm{DEHP} m \\
\mathrm{OR} \text { and } 95 \% \mathrm{Cl}\end{array}$ & $\begin{array}{c}\Sigma \mathrm{DiNP} \\
\mathrm{OR} \text { and } 95 \% \mathrm{Cl}\end{array}$ \\
\hline Wheeze within the last 2 years & $1.00(0.90,1.11)$ & $0.86(0.72,1.04)$ & $0.91(0.78,1.07)$ & $0.89(0.78,1.02)$ \\
Self-reported asthma & $1.02(0.82,1.27)$ & $0.95(0.67,1.36)$ & $0.98(0.72,1.33)$ & $0.99(0.77,1.28)$ \\
Doctor-diagnosed asthma & $0.91(0.73,1.12)$ & $0.80(0.57,1.13)$ & $0.91(0.68,1.21)$ & $0.94(0.73,1.21)$ \\
Use of medicine against asthma/cold & $0.99(0.88,1.13)$ & $0.86(0.70,1.08)$ & $0.87(0.72,1.04)$ & $0.85(0.72,1.00)$ \\
Self-reported eczema & $0.81^{*}(0.68,0.96)$ & $0.90(0.70,1.15)$ & $1.00(0.80,1.26)$ & $1.03(0.87,1.22)$ \\
Doctor-diagnosed eczema & $0.82(0.66,1.01)$ & $0.79(0.55,1.10)$ & $0.94(0.71,1.25)$ & $1.10(0.90,1.36)$ \\
Medicine against eczema & $0.88(0.70,1.10)$ & $0.84(0.58,1.23)$ & $1.02(0.72,1.43)$ & $1.24(1.00,1.55)$ \\
Self-reported rhinitis & $0.91(0.75,1.04)$ & $1.11(0.84,1.46)$ & $1.21(0.93,1.58)$ & $1.15(0.97,1.36)$ \\
\hline
\end{tabular}

Abbreviations: OR odds ratio; $95 \%$ Cl $95 \%$ confidence interval; MEP monoethyl phthalate; $\Sigma M B P$ Monobutyl phthalate (i $+\mathrm{n}$ ), $\Sigma$ DiNP $m$ sum of Di-isonyl phthalate metabolites; $\Sigma D E H P_{m}$ sum of Di-2-ethylhexyl phthalate metabolites

Note: ORs were adjusted for maternal age, maternal education, parity and family history of asthma/allergy. ${ }^{*}=p<0.05$ 
Information on allergy symptoms was obtained from questionnaires, which may be less accurate than the standard diagnostic criteria used by doctors. However, we used a modified version of the validated ISAAC questionnaire and misclassification of symptoms is unlikely to be related to phthalate exposure. Furthermore, more urine samples collected throughout pregnancy would have minimized the risk of misclassification due to temporal exposure variability. Given that the most vulnerable time for exposure to endocrine disrupting chemicals during pregnancy has not yet been determined, we may have misclassified exposures by measuring concentrations in the third trimester. Such nondifferental misclassifications can possibly underestimate outcomes related to phthalate exposure, which may explain our odds ratios close to 1 . We detected a wide variation of phthalate concentrations in the urine samples (Table 3). The wide variation is normal for human-biomonitoring studies of phthalates, and several longitudinal studies show that the intraindividual variation of the phthalates are most often lower than the interindividual variation [6,34].

Although our cohort was relatively large, few children reported allergic symptoms, which made it difficult to adjust for more covariates without losing statistical power. Thus, we did not account for the contribution of childhood exposures, although studies have found association between postnatal phthalate exposure and development of asthma and allergy [10, 35]. Likewise, we did not adjust for exposure to other phthalates or other endocrine disrupting chemicals. Our correlation analysis showed moderate to high correlation between phthalate metabolites and distinguishing the effect of exposure to one phthalate from another phthalate is difficult. In addition, we tested many potential associations and our significant result may be due to chance.

\section{Conclusions}

In this low exposed prospective mother-child cohort we found no consistent association between maternal phthalate exposure and asthma and eczema in the offspring aged 5 -years. Prenatal exposure to DiNP and DEHP was associated with rhinitis, although not significantly, possibly due to a relatively small number of 5-year-old children with rhinitis. Given the widespread use of phthalates, the possible association with rhinitis is of public health concern. It is therefore important to follow up the children with allergy testing, lung function assessment and phthalate exposure measurements, as the prevalence and diagnostic accuracy of allergic diseases will increase with age.

\section{Abbreviations}

BMI: Body Mass Index; DEHP: Di-2-ethylhexyl phthalate; DiNP: Diisononyl phthalate; GA: Gestational age; ISAAC: International Study of Asthma and Allergies in Childhood; Ln: Natural logarithm; LOD: Limit of detection; MBP: Mono-butyl phthalate; MBzP: Mono-benzyl phthalate; MCiOP: Monocarboxy-iso-octyl phthalate; MECPP: Mono-2-ethyl-5-carboxypentyl phthalate; MEHHP: Mono-2-ethyl-5-hydroxyhexyl phthalate; MEHP: Mono-2-ethylhexyl phthalate; MEOHP: Mono-2-ethyl-5-oxohexyl phthalate; MEP: Monoethyl phthalate; MHiNP: Mono-hydroxy-iso-nonyl phthalate; MiBP: Mono-iso-butyl phthalate; MiNP: Mono-iso-nonyl phthalate; MnBP: Mono-n-butyl phthalate; MOiNP: Mono-oxo-iso-nonyl phthalate; OCC: Odense Child Cohort

\section{Acknowledgements}

The families in Odense Child Cohort are acknowledged for their participation and commitment. The staff at Hans Christian Andersen's Children's Hospital and at the Department of Growth and Reproduction are acknowledged for, respectively, their careful examination of the children and phthalate analysis.

\section{Authors' contributions}

CJ conceived and designed the analysis, performed the analysis and wrote the manuscript. $\mathrm{AH}$ and $\mathrm{SH}$ conceived and designed the analysis and assisted in the analysis of the allergic outcomes. CAGT and IHB contributed analysis tools and helped performing the statistical analysis. HBK conceived and designed the analysis and collected the data. AMA and HF measured and analyzed the urinary phthalate levels. TKJ conceived and designed the analysis, contributed data and supervised the project. All authors read and approved the final manuscript.

\section{Funding}

This work was supported by the Danish Center for Hormone Disrupting Chemicals, the Danish Council for Independent Research, Medical Sciences (4004-00352B and 8020-00123B), Odense University Hospital and Region of Southern Denmark, the Municipality of Odense, the Mental Health Service of the Region of Southern Denmark, Odense University Hospital Research Foundation and Odense University Hospital Undergraduate Foundation, Odense Patient data Explorative Network (OPEN), the Novo Nordisk Foundation (Grant NNF15OC00017734 and NNF17OC0029404) and Helsefonden. The LCMS/MS equipment was financially supported by the Velux Foundation.

\section{Availability of data and materials}

The dataset supporting the conclusions of this article is available upon request.

Ethics approval and consent to participate

All parents received oral and written information about the overall projects in OCC and gave written consent for their participation. The study was performed in accordance with the Helsinki Declaration II, and approved by the Ethical Committee (Project ID S-20090130) and the Danish Data Protection Agency (13/16028).

\section{Consent for publication}

Not applicable.

\section{Competing interests}

The authors declare that they have no competing interests.

\section{Author details}

${ }^{1}$ Department of Environmental Medicine, Institute of Public Health, University of Southern Denmark, J.B. Winsløwsvej 17A, 5000 Odense, Denmark. ${ }^{2}$ Hans Christian Andersen Children's Hospital, Odense University Hospital, Odense, Denmark. ${ }^{3}$ Environmental Risk and Health Unit, Flemish Institute for Technological Research (VITO), Mol, Belgium. ${ }^{4}$ Department of Biomedical Sciences, University of Antwerp, 2000 Antwerp, Belgium. ${ }^{5}$ Odense Patient data Explorative Network (OPEN), Odense, Denmark. ${ }^{6}$ Department of Growth and Reproduction, Rigshospitalet, Copenhagen University Hospital,

Copenhagen, Denmark. ${ }^{7}$ International Center for Research and Research Training in Endocrine Disruption of Male Reproduction and Child Health (EDMaRC), Rigshospitalet, University of Copenhagen, Copenhagen, Denmark.

Received: 4 November 2019 Accepted: 28 February 2020

Published online: 13 March 2020

\section{References}

1. Henriksen L, Simonsen J, Haerskjold A, Linder M, Kieler H, Thomsen SF, Stensballe LG. Incidence rates of atopic dermatitis, asthma, and allergic rhinoconjunctivitis in Danish and Swedish children. J Allergy Clin Immunol. 2015;136(2):360-366e362

2. Herzog R, Cunningham-Rundles S. Pediatric asthma: natural history, assessment and treatment. Mt Sinai J Med. 2012;78(5):645-60. 
3. Thavagnanam S, Williamson G, Ennis M, Heaney LG, Shields MD. Does airway allergic inflammation pre-exist before late onset wheeze in children? Pediatr Allergy Immunol. 2010;21(7):1002-7.

4. Benjamin S, Masai E, Kamimura N, Takahashi K, Anderson RC, Faisal PA Phthalates impact human health: epidemiological evidences and plausible mechanism of action. J Hazard Mater. 2017;340:360-83.

5. Wang IJ, Lin CC, Lin YJ, Hsieh WS, Chen PC. Early life phthalate exposure and atopic disorders in children: a prospective birth cohort study. Environ Int. 2014;62:48-54

6. Assens M, Frederiksen H, Petersen JH, Larsen T, Skakkebaek NE, Juul A, Andersson AM, Main KM. Variations in repeated serum concentrations of UV filters, phthalates, phenols and parabens during pregnancy. Environ Int. 2019;123:318-24.

7. Buckley JP, Quiros-Alcala L, Teitelbaum SL, Calafat AM, Wolff MS, Engel SM. Associations of prenatal environmental phenol and phthalate biomarkers with respiratory and allergic diseases among children aged 6 and 7years. Environ Int. 2018;115:79-88.

8. Whyatt RM, Perzanowski MS, Just AC, Rundle AG, Donohue KM, Calafat AM, Hoepner LA, Perera FP, Miller RL. Asthma in inner-city children at 5-11 years of age and prenatal exposure to phthalates: the Columbia Center for Children's environmental health cohort. Environ Health Perspect. 2014;122(10):1141-6.

9. Stelmach I, Majak P, Jerzynska J, Podlecka D, Stelmach W, Polanska K, Ligocka D, Hanke W. The effect of prenatal exposure to phthalates on food allergy and early eczema in inner-city children. Allergy Asthma Proc. 2015;36(4):72-8.

10. Ku HY, Su PH, Wen HJ, Sun HL, Wang CJ, Chen HY, Jaakkola JJ, Wang SL. Prenatal and postnatal exposure to phthalate esters and asthma: a 9-year follow-up study of a Taiwanese birth cohort. PLoS One. 2015;10(4):e0123309.

11. Soomro MH, Baiz N, Philippat C, Vernet C, Siroux V, Nichole Maesano C, Sanyal S, Slama R, Bornehag CG, Annesi-Maesano I. Prenatal exposure to phthalates and the development of eczema phenotypes in male children: results from the EDEN mother-child cohort study. Environ Health Perspect. 2018;126(2):027002.

12. Just AC, Whyatt RM, Perzanowski MS, Calafat AM, Perera FP, Goldstein IF, Chen Q, Rundle AG, Miller RL. Prenatal exposure to butylbenzyl phthalate and early eczema in an urban cohort. Environ Health Perspect. 2012;120(10):1475-80.

13. Herberth G, Pierzchalski A, Feltens R, Bauer M, Roder S, Olek S, Hinz D, Borte M, von Bergen $\mathrm{M}$, Lehmann I. Prenatal phthalate exposure associates with low regulatory T-cell numbers and atopic dermatitis in early childhood: Results from the LINA mother-child study. J Allergy Clin Immunol. 2017;139(4):1376-9 e1378.

14. Ait Bamai Y, Miyashita C, Araki A, Nakajima T, Sasaki S, Kishi R. Effects of prenatal di (2-ethylhexyl) phthalate exposure on childhood allergies and infectious diseases: the Hokkaido study on environment and Children's health. Sci Total Environ. 2018;618:1408-15.

15. Berger K, Eskenazi B, Balmes J, Holland N, Calafat AM, Harley KG. Associations between prenatal maternal urinary concentrations of personal care product chemical biomarkers and childhood respiratory and allergic outcomes in the CHAMACOS study. Environ Int. 2018;121(Pt 1):538-49.

16. Smit LA, Lenters $V$, Hoyer BB, Lindh $\mathrm{CH}$, Pedersen HS, Liermontova I, Jonsson BA, Piersma AH, Bonde JP, Toft G, et al. Prenatal exposure to environmental chemical contaminants and asthma and eczema in schoolage children. Allergy. 2015;70(6):653-60.

17. Jahreis S, Trump S, Bauer M, Bauer T, Thurmann L, Feltens R, Wang Q, Gu L, Grutzmann K, Roder S, et al. Maternal phthalate exposure promotes allergic airway inflammation over 2 generations through epigenetic modifications. J Allergy Clin Immunol. 2018;141(2):741-53.

18. Vernet C, Pin I, Giorgis-Allemand L, Philippat C, Benmerad M, Quentin J, Calafat AM, Ye X, Annesi-Maesano I, Siroux V, et al. In utero exposure to select phenols and phthalates and respiratory health in five-year-old boys: a prospective study. Environ Health Perspect. 2017;125(9):097006.

19. Gascon M, Casas M, Morales E, Valvi D, Ballesteros-Gomez A, Luque N, Rubio S, Monfort N, Ventura R, Martinez D, et al. Prenatal exposure to bisphenol a and phthalates and childhood respiratory tract infections and allergy. J Allergy Clin Immunol. 2015;135(2):370-8

20. Kyhl HB, Jensen TK, Barington T, Buhl S, Norberg LA, Jorgensen JS, Jensen DF, Christesen HT, Lamont RF, Husby S. The Odense child cohort: aims, design, and cohort profile. Paediatr Perinat Epidemiol. 2015;29(3):250-8.

21. Frederiksen $H$, Jensen TK, Jorgensen N, Kyhl HB, Husby S, Skakkebaek NE, Main KM, Juul A, Andersson AM. Human urinary excretion of non-persistent environmental chemicals: an overview of Danish data collected between 2006 and 2012. Reproduction (Cambridge, England). 2014;147(4):555-65.

22. Frederiksen $\mathrm{H}$, Jorgensen $\mathrm{N}$, Andersson AM. Correlations between phthalate metabolites in urine, serum, and seminal plasma from young Danish men determined by isotope dilution liquid chromatography tandem mass spectrometry. J Analyticail Toxicol. 2010;34(7):400-10.

23. Olesen TS, Bleses D, Andersen HR, Grandjean P, Frederiksen $H$, Trecca F, Bilenberg N, Kyhl HB, Dalsager L, Jensen IK, et al. Prenatal phthalate exposure and language development in toddlers from the Odense Child Cohort. Neurotoxicology Teratology. 2018;65(Jauary-February 2018):34-41.

24. Jensen TK, Frederiksen H, Kyhl HB, Lassen TH, Swan SH, Bornehag C-G, Skakkebaek NE, Main KM, Lind DV, Husby S, et al. Prenatal exposure to phthalates and anogenital distance in male infants from a low-exposed Danish cohort (2010-2012). Environ Health Perspect. 2016;124(7):1107-13.

25. Middleton DR, Watts MJ, Lark RM, Milne CJ, Polya DA. Assessing urinary flow rate, creatinine, osmolality and other hydration adjustment methods for urinary biomonitoring using NHANES arsenic, iodine, lead and cadmium data. Environ Health. 2016;15(1):68.

26. Abdel Daiem MM, Rivera-Utrilla J, Ocampo-Pérez R, Méndez-Díaz JD, Sánchez-Polo M. Environmental impact of phthalic acid esters and their removal from water and sediments by different technologies - a review. J Environ Manag. 2012;109:164-78.

27. Pyun BY. Natural history and risk factors of atopic dermatitis in children. Allergy Asthma Immunol Res. 2015;7(2):101-5.

28. Kuo CH, Hsieh CC, Kuo HF, Huang MY, Yang SN, Chen LC, Huang SK, Hung $\mathrm{CH}$. Phthalates suppress type I interferon in human plasmacytoid dendritic cells via epigenetic regulation. Allergy. 2013;68(7):870-9.

29. Pei X, Duan Z, Ma M, Zhang Y, Guo L. Role of Ca/CaN/NFAT signaling in IL-4 expression by splenic lymphocytes exposed to phthalate (2-ethylhexyl) ester in spleen lymphocytes. Mol Biol Rep. 2014;41(4):2129-42.

30. Bao K, Reinhardt RL. The differential expression of IL-4 and IL-13 and its impact on type-2 immunity. Cytokine. 2015;75(1):25-37.

31. Miller MD, Marty MA. Impact of environmental chemicals on lung development. Environ Health Perspect. 2010;118(8):1155-64.

32. Han Y, Wang X, Chen G, Xu G, Liu X, Zhu W, Hu P, Zhang Y, Zhu C, Miao J. Di-(2-ethylhexyl) phthalate adjuvantly induces imbalanced humoral immunity in ovalbumin-sensitized BALB/C mice ascribing to T follicular helper cells hyperfunction. Toxicology. 2014;324:88-97.

33. Laerum BN, Svanes C, Wentzel-Larsen T, Gulsvik A, Torén K, Norrman E, Gíslason T, Janson C, Omenaas E. Young maternal age at delivery is associated with asthma in adult offspring. Resp Med. 2007;101(7):1431-8.

34. Mouritsen A, Frederiksen H, Sørensen K, Aksglaede L, Hagen C, Skakkebaek NE, Main KM, Andersson AM, Juul A. Urinary phthalates from 168 girls and boys measured twice a year during a 5-year period: associations with adrenal androgen levels and puberty. J Clin Endocrinol Metab. 2013;98(9):3755-64.

35. Shi W, Lin Z, Liao C, Zhang J, Liu W, Wang X, Cai J, Zou Z, Wang H, Norback $D$, et al. Urinary phthalate metabolites in relation to childhood asthmatic and allergic symptoms in Shanghai. Environ Int. 2018;121(Part 1):276-86.

\section{Publisher's Note}

Springer Nature remains neutral with regard to jurisdictional claims in published maps and institutional affiliations.

Ready to submit your research? Choose BMC and benefit from:

- fast, convenient online submission

- thorough peer review by experienced researchers in your field

- rapid publication on acceptance

- support for research data, including large and complex data types

- gold Open Access which fosters wider collaboration and increased citations

- maximum visibility for your research: over $100 \mathrm{M}$ website views per year

At $\mathrm{BMC}$, research is always in progress.

Learn more biomedcentral.com/submissions 